\title{
La participación de la audiencia en la televisión: de la audiencia activa a la social
}

\author{
Reseña del libro: Quintas-Froufe, N. y González-Neira, A. \\ (coords.) (2015). La participación de la audiencia en la \\ televisión: de la audiencia activa a la social. \\ Madrid: Asociación para la Investigación de Medios de \\ Comunicación (AIMC)
}

\section{Judith Clares-Gavilán ${ }^{1}$}

Recibido: 2016-04-22

Enviado a pares: 2016-04-22
Aprobado por pares: 2016-04-29

Aceptado: 2016-04-29

DOI: 10.5294/pacla.2016.19.3.11

Para citar este artículo / to reference this article / para citar este artigo

Clares-Gavilán, J. (2016). La participación de la audiencia en la televisión: de la audiencia activa a la social. Palabra Clave 19(3), 938-941. DOI: 10.5294/pacla.2016.19.3.11

La participación de la audiencia en la televisión: de la audiencia activa a la social es un libro coordinado por Natalia Quintas-Froufe y Ana González-Neira. Coeditado por la Universidad de La Coruña y la Asociación para la Investigación de Medios de Comunicación (AIMC), es una obra innovadora que aborda los cambios y las oportunidades que debe afrontar la medición y el análisis de audiencia en televisión con la irrupción del consumo multidispositivo y bajo demanda y el creciente auge de las redes sociales. Estos tres elementos han dado paso a un nuevo espectador, más activo que nunca, que forma parte de la denominada audiencia social.

Estructurado en ocho capítulos, combina el análisis de la evolución de las características de la audiencia, su medición y la evolución de la tele-

$1 \quad$ Universitat Oberta de Catalunya, España. jclares@uoc.edu 
visión con la irrupción de internet, con el estudio de tres casos que ilustran el nuevo papel y empoderamiento del espectador.

A través del primer capítulo, Ana González-Neira y Natalia QuintasFroufe plantean una revisión teórica del término televisión social a partir del análisis de las distintas aproximaciones propuestas desde disciplinas, como la ingeniería, la informática y la comunicación. Un recorrido histórico que permite entender cómo ha evolucionado el término desde 2007 y que lleva a las autoras a proponer una nueva definición que integra los conceptos de televisión interactiva, redes sociales y segundas pantallas. Este primer capítulo presenta la hoja de ruta de la obra e introduce los principales aspectos que veremos en los capítulos sucesivos.

En el segundo capítulo, Lázaro Echegaray nos aproxima al concepto prosumer, con el objetivo de entender el nuevo papel de la audiencia en relación con empresas, marcas y anunciantes. Una buena comunicación pasará por saber localizar el prosumer con mayor capacidad de influencia y por la capacidad que tenga la marca de involucrarlo en su proceso de generación de influencia publicitaria. Esta nueva realidad ha llevado al surgimiento de nuevos términos y a la necesidad de crear nuevos perfiles y papeles profesionales en los departamentos de marketing de las compañías: influencers marketing, viralidad de contenidos, engagement o community manager, entre otros.

Elena Neira destaca en el tercer capítulo la necesidad de encontrar sistemas de medición capaces de integrar el análisis del consumo televisivo lineal, bajo demanda y multidispositivo, sin descuidar el peso de los datos cualitativos que aporta la medición de la actividad de la audiencia en redes sociales. Muestra también cómo, más allá de la medición de audiencias, el análisis de datos (big data), se ha convertido en el gran protagonista en la toma de decisiones en el sector televisivo. Puede influir en la propuesta de nuevos shows, incluso en la decisión de cancelación de un determinado programa.

A partir de los siguiente tres capítulos, se presenta el análisis de tres estudios de caso. 
El primero de ellos, elaborado por Luis Deltell, Florencia Claes y Mari Luz Congosto, revisa los resultados de la investigación desarrollada en torno a la monitorización de los tuiteos emitidos de la retransmisión por RTVE de la gala de entrega de los Premios Goya en las ediciones 2013 a 2015, con el objetivo de abordar los conceptos de urdimbre comunicativa y enjambre social. Con el análisis combinado de datos cuantitativos y cualitativos en torno a dichas emisiones, los autores muestran sus conclusiones alrededor de la formación de líderes de opinión y el impacto de los tuiteos más relevantes.

El segundo estudio de caso se centra en el análisis de la audiencia social a través de Twitter en torno al programa televisivo La Voz, de Telecinco. Elaborado por Carmen Marta-Lazo y Adriana Aguilera Gonzalo, analizan el impacto de las redes sociales en el contenido y en la audiencia de los programas de televisión.

Con el último estudio de caso, Jorge Gallardo-Camacho y Eva Lavín de Las Heras se centran en el análisis de los datos de consumo obtenidos por Rentrak del portal Yomvi. A partir de estos datos, nos muestran cuáles son los contenidos más demandados y cuáles son los hábitos de consumo de los espectadores de la plataforma de VOD (video bajo demanda 'video on demand') de la televisión de pago española Movistar+.

A lo largo de los dos últimos capítulos, se abordan dos nuevos temas que nos llevan a tener una visión completa acerca de los retos y las oportunidades que plantean las nuevas audiencias en televisión.

El primero, de Félix Ortega, se centra en el uso de las tabletas y de los teléfonos inteligentes en el consumo de televisión mediante aplicaciones. Estudia los usos y consumos de las aplicaciones por parte de los millenials (milénicos). Para ello, analiza las estrategias y la evolución del modelo de negocio de los principales grupos televisivos españoles: Mediaset, Atresmedia, CRTVE y Movistar+, sin descuidar las iniciativas seguidas por actores globales de la envergadura de Netflix, Hulu, Amazon o Wuaki.tv. 
Natalia Papí-Gálvez cierra el libro con un capítulo dedicado al análisis comparativo de la audiencia tradicional frente a la audiencia en línea con el objetivo de valorar sus características, beneficios e inconvenientes, dentro del mercado publicitario.

Una aproximación que cierra y da coherencia al conjunto de una obra que abarca todos los aspectos posibles relacionados con los nuevos y viejos sistemas de medición de audiencia, las características de la audiencia social y su impacto en los distintos ámbitos analizados que, como hemos visto, van más allá de la tradicional negociación entre cadenas de televisión y anunciantes. 